\title{
Research on evolution game of clothing enterprises' carbon emission reduction investment considering free riding behavior
}

\author{
Hangxin Guo ${ }^{1}$, Zheng Liu ${ }^{1,2 *}$, Mengmeng $\mathrm{Zhao}^{3}$ and Huihui Wang ${ }^{4}$ \\ 1. School of Management, Shanghai University of Engineering Science, Shanghai, 201620; \\ 2. Antai College of Economics and Management, Shanghai Jiao Tong University, Shanghai, 200240 \\ 3. School of textile and clothing, Shanghai University of Engineering Science, Shanghai, 201620; \\ 4. Business school, University of Shanghai for Science and Technology, Shanghai 200093
}

\begin{abstract}
: "low carbon economy" puts forward new requirements for carbon emission reduction in all links of the supply chain. This paper takes the three-level clothing supply chain composed of government, supplier and manufacturer as the research object, considering the "free riding behavior" of clothing supplier and manufacturer, by constructing the three-party evolutionary game model, using the replication dynamic equation to analyze the evolution process of the three actors, and studies the influence of parameter change on the strategy selection of each agent. Finally, the simulation is carried out by Matlab. The results show that the strategies are affected by the government's punishment, the "free ride" revenue of suppliers and manufacturers, and the cost of carbon emission reduction investment. Finally, based on the analysis results, some suggestions are put forward for enterprises to invest in carbon emission reduction.
\end{abstract}

\section{Introduction}

With the increasingly prominent environmental problems, low carbon is regarded as the basis of national economic development in the world. As the largest emitter of carbon dioxide, China has the responsibility and obligation to contribute to carbon emission reduction, which requires all-round social cooperation and participation [1]. The investment of carbon emission reduction leads to the decrease of enterprise profits, so usually enterprises are not willing to actively invest in carbon emission reduction, which requires the supervision of government departments. At the same time, the supervision of government departments needs cost, which leaves opportunities for enterprises not to carry out carbon emission reduction or "hitchhiking". Therefore, using evolutionary game theory to analyze the input behavior of carbon emission reduction has certain significance. In recent years, many scholars have used evolutionary game theory to study carbon emission reduction investment.

$\mathrm{Z}$ Liu et al. used edge computing to intelligently optimize the supply chain under the constraint of carbon tax, so as to achieve the dual goals of economic benefits and emission reduction [2]. J Z Xu et al. studied the factors that affect the main strategies of the three-party game by building the three-party evolutionary game model [3]. S C Tang et al. studied the carbon emission reduction strategy of supply chain under the leadership of manufacturer and retailer based on social responsibility [4]. J P Xu et al. studied the dynamic equilibrium strategy of the integration of procurement, coal blending and distribution in thermal power enterprises, and proved that the modified method can achieve low-carbon economy through examples [5]. S P Sun et al constructed a tripartite evolutionary game model and analyzed the local stability of the model by using the dynamic replication equation [6].

J L Jiao et al. studied the influence of carbon quota, supervision cost and other factors on evolutionary stability strategy under dynamic and static reward and punishment system [7]. F J Wang et al. studied the impact of government pressure on the carbon emission reduction performance of enterprises, and the research shows that the impact is positive [8]. D D Fan et al. used the Nash model and the Steinberg model to analyze the impact of government subsidies on the carbon emission reduction decision-making of enterprises under different power structures [9]. X Y Cao et al. studied the influence of carbon tax policies and government subsidies on the optimal carbon emission reduction and order quantity of enterprises [10]. $\mathrm{R}$ Zhao et al. analyzed how the government and the enterprise choose the strategy to achieve the emission reduction target [11];

The existing literature mainly studies the impact of government on the decision-making behavior of all parties and the emission reduction decision-making behavior of upstream and downstream enterprises in the supply chain, but few literatures take "free riding behavior" into account Based on this, this paper uses evolutionary game theory and numerical simulation method to study the the asymmetric dynamic evolution process of the three parties in the game. Finally, based on the analysis results, some suggestions are put forward for enterprises to invest in carbon emission reduction.

*Corresponding author. Email: 03140011@sues.edu.cn 


\section{The construction of tripartite game model}

This paper takes the three-level clothing supply chain composed of government, supplier and manufacturer as the research object, and studies the evolution process of the tripartite game. The emission reduction investment refers to the behavior of investment to reduce carbon dioxide emissions in the process of production, processing, transportation, retail or use [16]. It's raw products are lowcarbon products, and the products without carbon emission reduction investment are ordinary products.

In order to facilitate the analysis, the following assumptions are made for this paper:

Hypothesis 1: The probability of government choosing the "regulatory" strategy is $x$, then the probability of choosing the "non regulatory" strategy is $1-x$; the probability of suppliers and manufacturers choosing the "carbon emission reduction investment" strategy is $y$ and $Z$.

Hypothesis 2: the cost of government regulation is $C$; when both the supplier and the manufacturer invest in carbon emission reduction, the environmental benefit obtained by the government is $W_{1}$; when only the supplier does it, it is $W_{2}$; when only the manufacturer does it, it is $W_{3}$; when neither party does it, it is $W_{4}$, and the fines imposed by the government are $F_{s}$ and $F_{m}$ respectively.

Hypothesis 3: when no carbon emission reduction investment is made, the cost of the supplier and the manufacturer is $C_{s}$ and $C_{m}$, and the revenue is $R_{s}$ and $R_{\mathrm{m}}$. when the supplier is making the investment, the revenue increase rate is $\alpha_{0}$, and when both parties are making the investment, it is $\alpha_{1}$; similarly, when the manufacturer is making the investment, the revenue increase rate is $\beta_{0}$, and when both parties are making the investment, it is $\beta_{1}$.

Hypothesis 4: when faced with the opportunity of carbon emission reduction investment, when one enterprise invests in emission reduction, the other enterprise can "hitchhike". As a result, the manufacturer's revenue from hitchhiking is $R_{m}^{\prime}$ and the supplier's revenue is $R_{s}^{\prime}$.

\section{Model solution}

Based on the assumptions and parameters, eight strategic combinations of the tripartite evolutionary game are constructed. Government regulation is recorded as $A_{1}$, no regulation as $A_{2}$, suppliers and manufacturers' carbon emission reduction investment is recorded as $A_{3}$ and $A_{5}$ respectively, and no carbon emission reduction investment is recorded as $A_{4}$ and $A_{6}$ respectively. Then the three-party income after the game is shown in table 1 .

Table 1. Benefits of tripartite game

\begin{tabular}{|c|c|c|c|c|}
\hline \multirow{2}{*}{ Event } & \multicolumn{2}{|c|}{$A_{1}$} & \multicolumn{2}{c|}{$A_{2}$} \\
\cline { 2 - 5 } & $A_{3}$ & $A_{4}$ & $A_{3}$ & $A_{4}$ \\
\hline \multirow{4}{*}{$A_{5}$} & $W_{1}-C$ & $W_{3}-C+F_{s}$ & $W_{1}$ & $W_{3}$ \\
& $\left(1+\alpha_{1}\right) R_{s}-C_{s}$ & $R_{s}^{\prime}-F_{s}$ & $\left(1+\alpha_{1}\right) R_{s}-C_{s}$ & $R_{s}^{\prime}$ \\
& $\left(1+\beta_{1}\right) R_{m}-C_{m}$ & $\left(1+\beta_{0}\right) R_{m}-C_{m}$ & $\left(1+\beta_{1}\right) R_{m}-C_{m}$ & $\left(1+\beta_{0}\right) R_{m}-C_{m}$ \\
\hline \multirow{3}{*}{$A_{6}$} & $W_{2}-C+F_{m}$ & $W_{4}-C+F_{s}+F_{m}$ & $W_{2}$ & $W_{4}$ \\
& $\left(1+\alpha_{0}\right) R_{s}-C_{s}$ & $R_{s}-F_{s}$ & $\left(1+\alpha_{0}\right) R_{s}-C_{s}$ & $R_{s}$ \\
& $R_{m}^{\prime}-F_{m}$ & $R_{m}-F_{m}$ & $R_{m}^{\prime}$ & $R_{\mathrm{m}}$ \\
\hline
\end{tabular}

\section{Model analysis}

\subsection{Stability strategy of government departments}

Assuming that the expected benefit of the government's choice of "regulatory" strategy is $U_{g y}$, that of "non regulation" is $U_{g n}$, and the average expected revenue of the government is $\overline{U_{g}}$, then:

$$
\begin{aligned}
& U_{g y}=y z\left(W_{1}-W_{2}-W_{3}-W_{4}\right)+z\left(W_{3}-W_{4}-F_{m}\right)+y\left(W_{2}-W_{4}-F_{s}\right)+W_{4}-C+F_{s}+F_{m} \\
& U_{g n}=y z a_{3}+y(1-z) a_{7}+(1-y) z a_{4}+(1-y)(1-z) a_{8}=y z\left(W_{1}-W_{2}-W_{3}+W_{4}\right)+y\left(W_{2}-W_{4}\right)+z\left(W_{3}-W_{4}\right)+W_{4} \\
& \overline{U_{g}}=x U_{g y}+(1-x) U_{g n}=-x z F_{m}-x y F_{s}+x\left(F_{s}+F_{m}-C\right)+y z\left(W_{1}-W_{2}-W_{3}+W_{4}\right)+y\left(W_{2}-W_{4}\right)+z\left(W_{3}-W_{4}\right)+W_{4}
\end{aligned}
$$

The replication dynamic equation of the government is as follows:

$$
F(x)=\frac{d x}{d t}=x\left(U_{g y}-\overline{U_{g}}\right)=x(1-x)\left(F_{m}+F_{s}-C-z F_{m}-y F_{s}\right)
$$

$$
\begin{aligned}
& \text { If } F(x)=0, \text { then } x_{1}=0, x_{2}=1 \text {, } \\
& y_{0}=\frac{F_{m}+F_{s}-C-z F_{m}}{F_{s}} \text {. When } y=y_{0}, F(x) \equiv 0 \text {, }
\end{aligned}
$$

all levels are stable points; When $y \neq y_{0}$, then $x_{1}=0$ 
and $x_{2}=1$ are two stable points.

The derivation of equation (4) shows that:

$\frac{d F(x)}{d x}=(1-2 x)\left(F_{m}+F_{s}-C-z F_{m}-y F_{s}\right)$

(1)When $F_{m}+F_{s} \leq C,\left.\frac{d F(x)}{d x}\right|_{x_{1}=0}<0,\left.\frac{d F(x)}{d x}\right|_{x_{2}=1}>0$,

so $x_{1}=0$ is the evolutionary stability strategy;

(2) When $F_{m}+F_{s}>C$ :
When $y>\frac{F_{m}+F_{s}-C}{F_{m}+F_{s}},\left.\frac{d F(x)}{d x}\right|_{x_{1}=0}<0,\left.\frac{d F(x)}{d x}\right|_{x_{2}=1}>0$,

so $x_{1}=0$ is the evolutionary stability strategy;

When $y<\frac{F_{m}+F_{s}-C}{F_{m}+F_{s}},\left.\frac{d F(x)}{d x}\right|_{x_{1}=0}>0,\left.\frac{d F(x)}{d x}\right|_{x_{2}=1}<0$,

so $x_{1}=1$ is the evolutionary stability strategy;

Through the analysis, the government's evolution stability strategy is shown in figure 1 .

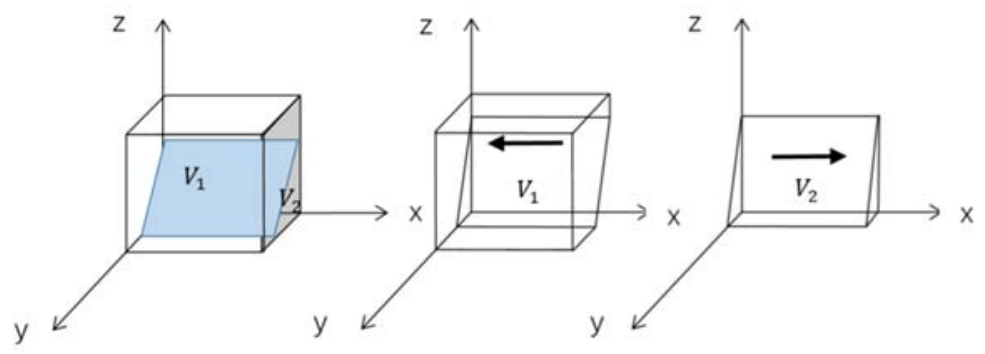

Figure 1. Supplier's impact on government strategy

It can be seen from figure 1 that when the initial state is in space $V_{1}, y>y_{0}$ and $x_{1}=0$ is the equilibrium point, because the cost of government supervision is greater than the benefit, the "no regulatory " strategy is chosen; When the initial state is in space $V_{2}, y<y_{0}$ and $x_{2}=1$ is the equilibrium point, and the government chooses the " regulatory" strategy.

Due to the cost pressure of government, some enterprises are opportunistic and pursue economic development unilaterally; If the government supervises and punishes the enterprises' extensive production, enterprises can be encouraged to actively invest in carbon emission reduction. Therefore, the government should play an active role to promote enterprises to do this.

\subsection{Stability strategy of supplier Department}

Assuming that the expected return of the supplier's choice of "carbon emission reduction input" strategy is $U_{s y}$, the expected return of the choice of "no carbon emission reduction input" strategy is $U_{s n}$, and the average expected return of the supplier is $\overline{U_{s}}$, then:

$\overline{U_{s}}=y U_{s y}+(1-y) U_{s n}=\left(\alpha_{1}-\alpha_{0}\right) y z R_{s}+\alpha_{0} y R_{s}-y C_{s}-x F_{s}+z R_{s}^{\prime}+(1-z) R_{s}+x y F_{s}-z y R_{s}^{\prime}+z y R_{s}$

The replication dynamic equation of the supplier is as follows:

$F(y)=\frac{d y}{d t}=y\left(U_{s y}-\overline{U_{s}}\right)=y(1-y)\left\{\alpha_{0} R_{s}-C_{s}-\left[R_{s}^{\prime}-\left(\alpha_{1}-\alpha_{0}+1\right) R_{s}\right] z+x F_{s}\right\}$

If $F(y)=0$, then $y_{1}=0, y_{2}=1$,

(6) shows that:

$z_{0}=\frac{\alpha_{0} R_{s}-C_{s}+x F_{s}}{R_{s}^{\prime}-\left(\alpha_{1}-\alpha_{0}+1\right) R_{s}}$, and the derivation of equation

$$
\frac{d F(y)}{d y}=(1-2 y)\left\{\alpha_{0} R_{s}-C_{s}-\left[R_{s}^{\prime}-\left(\alpha_{1}-\alpha_{0}+1\right) R_{s}\right] z+x F_{s}\right\}
$$

(1)When $z=z_{0}, F(y) \equiv 0$, all levels are stable points;

(2)When $z<z_{0},\left.\frac{d F(y)}{d y}\right|_{y_{1}=0}>0,\left.\frac{d F(y)}{d y}\right|_{y_{2}=1}<0$,

so $y_{2}=1$ is the evolutionary stability strategy;
(3)When $z>z_{0},\left.\frac{d F(y)}{d y}\right|_{y_{1}=0}<0,\left.\frac{d F(y)}{d y}\right|_{y_{2}=1}>0$,

so $y_{1}=0$ is the evolutionary stability strategy;

Through the analysis, the evolution stability strategy of suppliers is shown in figure 2 . 


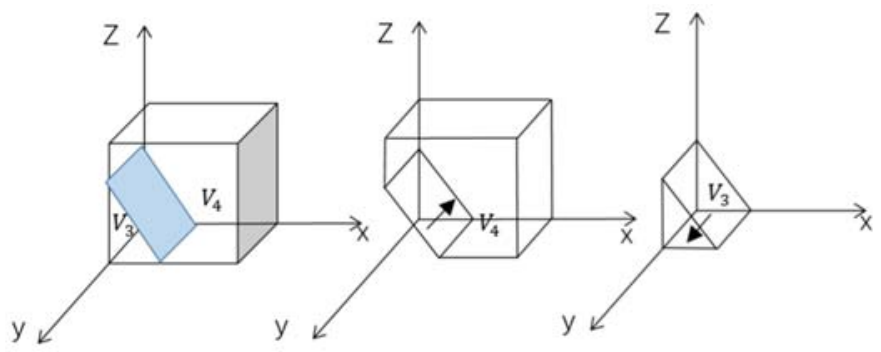

Figure 2. Manufacturer's impact on supplier strategy

It can be seen from figure 2 that when the initial state is in space $V_{3}$, there are $z<z_{0}$ and $y_{2}=1$ as the equilibrium point, and supplier chooses to invest in carbon emission reduction. At this time, enterprises tend to choose the investment strategy of carbon emission reduction in

\subsection{Manufacturer's stabilization strategy}

Suppose that the manufacturer's expected return for choosing "carbon emission reduction input" strategy is consideration of the fine mechanism existing in government supervision and their own net income. On the contrary, when in $V_{4}$, there is $z>z_{0}, y_{1}=0$ as the equilibrium point, and they choose the strategy of "no investment ".

$U_{m y}$, the expected return for choosing "no carbon emission reduction input" strategy is $U_{m n}$, and the manufacturer's average expected return is $\overline{U_{m}}$, then:

$\overline{U_{m}}=z U_{m y}+(1-z) U_{m n}=\left(\beta_{1}-\beta_{0}\right) y z R_{m}+\beta_{0} z R_{m}-z C_{m}-x F_{m}+y R_{m}^{\prime}+(1-y) R_{m}+x z F_{m}-y z\left(R_{m}^{\prime}-R_{m}\right)$

The replication dynamic equation of the manufacturer is as follows:

$$
F(z)=\frac{d z}{d t}=z\left(U_{m y}-\overline{U_{m}}\right)=z(1-z)\left\{\beta_{0} R_{m}-C_{m}+x F_{m}-y\left[R_{m}^{\prime}-R_{m}\left(\beta_{1}-\beta_{0}+1\right)\right]\right\}
$$

If $F(z)=0$, then $z_{1}=0, z_{2}=1$,

$y_{0}=\frac{\beta_{0} R_{m}-C_{m}+x F_{m}}{R_{m}^{\prime}-R_{m}\left(\beta_{1}-\beta_{0}+1\right)}$, and the derivation of equation (9) shows that:

$$
\frac{d F(z)}{d z}=(1-2 z)\left\{\beta_{0} R_{m}-C_{m}+x F_{m}-y\left[R_{m}^{\prime}-R_{m}\left(\beta_{1}-\beta_{0}+1\right)\right]\right\}
$$

(1)When $y=y_{0}, F(z) \equiv 0$, all levels are stable points;

(2)When $y<y_{0},\left.\frac{d F(z)}{d z}\right|_{z_{1}=0}>0,\left.\frac{d F(z)}{d z}\right|_{z_{2}=1}<0$,

so $z_{2}=1$ is the evolutionary stability strategy;

(3)When $y>y_{0},\left.\frac{d F(z)}{d z}\right|_{z_{1}=0}<0,\left.\frac{d F(z)}{d z}\right|_{z_{2}=1}>0$,

so $z_{1}=0$ is the evolutionary stability strategy;

Through the above analysis, the evolution stability strategy of the manufacturer is shown in figure 3.

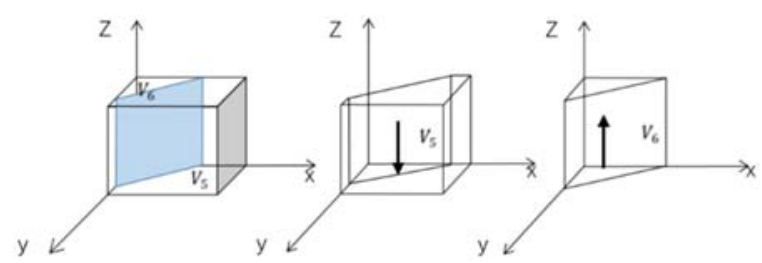

Figure 3. Supplier's impact on manufacturer strategy

It can be seen from Figure 3 that when the manufacturer's initial state is in space $V_{6}$, there is $y<y_{0}$, $z_{2}=1$ as the equilibrium point, and the manufacturer chooses the " investment" strategy. At this time, the enterprise will tend to choose the "investment" strategy considering the fine mechanism and its own net income situation existing in the government supervision; when in $V_{5}$, there is $y>y_{0}$, as the equilibrium point, which tends to choose" no investment "strategy.

Which strategy supplier and manufacturer will ultimately choose is related to the government's punishment mechanism and the free riding behavior of upstream and downstream enterprises. In order to make enterprises choose the strategy of " investment", it's necessary to properly use the government to supervise and guide the market regulation.

\subsection{Comprehensive analysis of game equilibrium strategy of fireworks among government, supplier and manufacturer}

Combined with figure 1,2 and 3 , the results of evolutionary game among government, supplier and manufacturer are summarized, as shown in table 2 . Because the following equilibrium states are not robust to small disturbances, there is no evolutionary stability policy (ESS) in the game process. 
Table 2. Equilibrium results of tripartite evolutionary game

\begin{tabular}{|c|c|c|c|}
\hline strategy combination & final strategy selection & strategy combination & final strategy selection \\
\hline$\left(V_{1}, V_{3}, V_{5}\right)$ & $\begin{array}{c}\text { (no regulation, investment, no } \\
\text { investment) }\end{array}$ & $\left(V_{2}, V_{3}, V_{5}\right)$ & $\begin{array}{c}\text { (regulation, investment, no } \\
\text { investment) }\end{array}$ \\
\hline$\left(V_{1}, V_{3}, V_{6}\right)$ & $\begin{array}{c}\text { (no regulation, investment, } \\
\text { investment) }\end{array}$ & $\left(V_{2}, V_{3}, V_{6}\right)$ & $\begin{array}{c}\text { (regulation, investment, } \\
\text { investment) }\end{array}$ \\
\hline$\left(V_{1}, V_{4}, V_{5}\right)$ & $\begin{array}{c}\text { (no regulation, no investment, no } \\
\text { investment) }\end{array}$ & $\left(V_{2}, V_{4}, V_{5}\right)$ & $\begin{array}{c}\text { (regulation, no investment, no } \\
\text { investment) }\end{array}$ \\
\hline$\left(V_{1}, V_{4}, V_{6}\right)$ & $\begin{array}{c}\text { (no regulation, investment, } \\
\text { investment) }\end{array}$ & $\left(V_{2}, V_{4}, V_{6}\right)$ & $\begin{array}{c}\text { (regulation, investment, } \\
\text { investment) }\end{array}$ \\
\hline
\end{tabular}

\section{Numerical simulation}

between supplier and manufacturer. Suppose the specific parameter settings are shown in table 3. Matlab

This paper only considers the situation of "free riding" is used to simulate the stability strategy results of three actors under the change of specific parameters.

Table 3. Specific parameter values

\begin{tabular}{|c|c|c|c|c|c|c|c|c|c|c|c|c|c|}
\hline $\begin{array}{c}\text { Parameter } \\
\text { symbols }\end{array}$ & $\alpha_{0}$ & $\alpha_{1}$ & $\beta_{0}$ & $\beta_{1}$ & $C$ & $C_{m}$ & $C_{\mathrm{s}}$ & $R_{s}$ & $R_{s}^{\prime}$ & $R_{m}$ & $R_{m}^{\prime}$ & $F_{s}$ & $F_{m}$ \\
\hline $\begin{array}{c}\text { Numerical } \\
\text { value }\end{array}$ & 0.235 & 0.455 & 0.245 & 0.375 & 7 & 13.5 & 8 & 35 & 52.5 & 57 & 71.5 & 9 & 6 \\
\hline
\end{tabular}

\subsection{The influence of government punishment on the equilibrium strategy of enterprises}

Figure 4 shows the impact of the change of government's punishment on the evolution results. Change the value of $F_{s}$ without changing any other parameters. As shown in

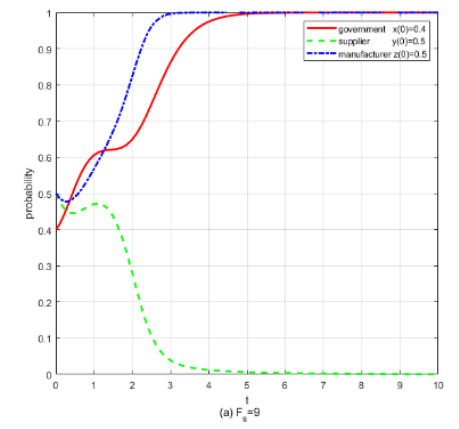

Figure 4. Impact of government punishment on tripartite equilibrium strategy

\subsection{The influence of cost on the equilibrium strategy of three parties}

Figure 5 shows the impact of cost input on the evolution results of the three parties. Other parameters remain unchanged, changing $C$ and $C_{m}$ respectively, as shown in the figure, from $C=7$ to $C=10$, the government tends to choose non regulatory strategy due to the increase of regulatory cost; when the manufacturer's the figure, the initial proportion of each entity is the same. After the reduction of the government's penalty for manufacturing supplier. The government's strategy has changed from regulatory to non regulatory, and the supplier choose "no investment" strategy due to the small punishment. At this time, the manufacturer choose "investment" strategy to get more benefits, so the supplier can get more benefits through free riding.

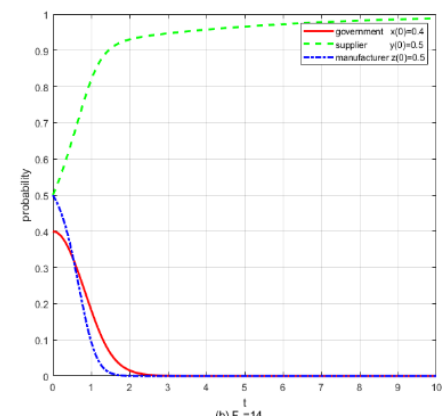

cost $C_{m}$ changes from 13.5 to 18 , the supplier tends to choose "investment" strategy, and the manufacturer eventually tends to choose "no investment" strategy. Because at this time, when the supplier is faced with greater punishment, the benefit generated by free riding is less than that generated by carbon emission reduction investment, so the supplier will finally adopt the carbon emission reduction investment strategy. Therefore, the government can change the equilibrium strategy of enterprises by increasing the punishment to enterprises and reducing the supervision cost. 

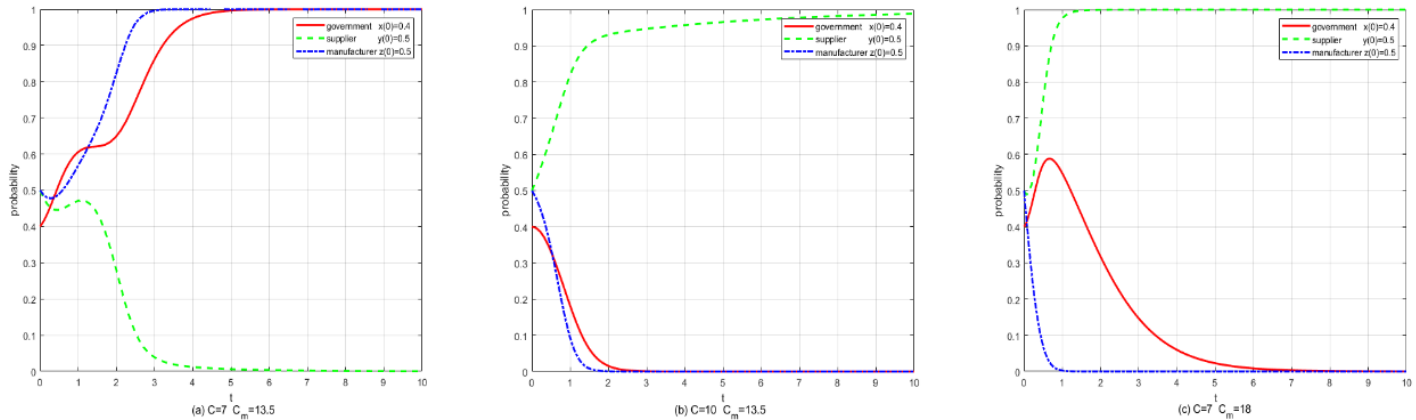

Figure 5. The impact of cost on the tripartite equilibrium strategy

\section{Conclusion and prospect}

Based on the existing research on the evolutionary game of carbon emission reduction investment, this paper considers the "free riding" behavior among clothing enterprises. By constructing a tripartite evolutionary game model, the evolution process of the three actors is analyzed by using the replication dynamic equation, and the influence of the strategy selection between the actors and the parameter change on the strategy selection of each actor is studied. Finally, Matlab is used for simulation. The results show that when the government chooses the regulatory strategy and the manufacturer (retailer) chooses to invest in carbon emission reduction, the retailer (manufacturer) will adopt the "free riding" strategy; At the same time, when the government punishment is low and the regulatory cost is high, the enterprise will also adopt this strategy.

In this regard, the government should cooperate with various departments, strengthen supervision, formulate reasonable punishment system, and set up carbon trading policies and carbon emission rights, so as to promote enterprises to carry out low-carbon emission reduction independently. Enterprises should increase efforts to independently develop carbon emission reduction equipment or technical means, and at the same time, by means of cooperation and coordination or revenue sharing contract, avoid "free riding" behavior.

\section{Acknowledgments}

The finding is sponsored by the National Social Science Fund of China (Grant No. 18CGL015).

\section{References}

1 Liu Z, Hu B and Zhao Y J 2020 Research on Intelligent Decision of Low Carbon Supply Chain Based on Carbon Tax Constraints in Human-Driven Edge Computing IEEE 08 48264-48273

2 Wang Q P, Zhao Z G and He F L 2014 Strategies Selection and Behavioral Evolution of CarbonEmission-Reduction Investment in Supply Chain Firms IEEM 28 180-189

$3 \mathrm{Xu} \mathrm{J} \mathrm{Z}$ and Lv X C 2014 Evolutionary Analysis Between Governments、Manufacting Enterprises and
Consumers on Low-Carbon Decision-making Behavior under the Background of Low-Carbon Economy Operations Research and Management Science 23 81-91

4 Tang S C, Liu Y X and Xiao T J 2020 Pricing and carbon emission reduction decision in a socially responsible supply chain Chinese Journal of Management Science 28 99-108

5 Xu J P, Feng Q, Lv C W and Huang. Q 2019 Lowcarbon electricity generation-based dynamic equilibrium strategy for carbon dioxide emissions reduction in the coal-fired power enterprise Enviro Sci Pollut Res 26 36732-53

6 Sun S P and Sun X Y 2016 Evolutionary Analysis Between Governments、Manufacting Enterprises and Consumers on Low-Carbon Decision-making Behavior under the Background of Low-Carbon Economy Operations Research and Management Science 25 113-9

7 Jiao J L, Chen J, Li L L and Li F Y 2017 A Study of Local Governments' and Enterprises' Actions in the Carbon Emission Mechanism of Subsidy or Punishment Based on the Evolutionary Game J Manag Sci China 25 140-150

8 Wang F J and Sun J Q 2019 Research on the impact of government pressure on the performance of carbon emission reduction of enterprises Forecasting 38 3744

9 Fan D D and Xu Q 2018 Decisions of Enterprises Carbon Emission Reduction and Government Subsidy in Different Power Structures Soft science 32 64-70

10 Cao X Y and Zhang J F 2018 Carbon Reduction Optimization and Coordination of Supply Chain under Carbon R eduction Subsidy and Carbon Tax Operations Research and Management Science 27 57-61

11 Zhao R, Neighbour G, Han J J, McGuire M and Deutz P 2012 Using game theory to describe strategy selection for environment risk and carbon emissions reduction in the green supply chain Journal of Loss Prevention in the Process Industries 25 927-36

12 Jones G, Plassmann $\mathrm{K}$ and York EH 2009 Vulnerability of exporting nations to the development of a carbon label in the United Kingdom Environmental Science \& Ploicy 12 479-490 